\title{
Danger of underground erosion and sinking of the building of pumped storage energy plant in Zagorsk
}

\author{
Andrey Lavrusevich ${ }^{1, *}$ \\ ${ }^{1}$ Moscow State University of Civil Engineering, 129337, 26, Yaroslavskoye Shosse, Moscow, Russia
}

\begin{abstract}
Using the probabilistic approach, authors consider the case of development of a dangerous geological phenomenon i.e. the large underground erosive channel, induced by a mechanical suffusion during construction of the pumped storage energy plant in Zagorsk (PSEP-2). Formation of the erosive channel has led to the formation of cavities with the diameter up to 10 metres in the middle and upper-quarternary, suffusion-unstable, the fluvial-and-glacial and lake-glacial deposits of the Moscow and Dnieper moraine. Thin deposits were the bearing basis of the concrete construction of the dam of PSEP-2 in Zagorsk. The lack of proper consideration of difficult engineering-and-geological conditions and the subsequent formation of emptiness has led to the unilateral draft of the building of PSEP-2 in Zagorsk. Draft of the building of PSEP-2 in Zagorsk has detained the start-up of the building into maintenance and has resulted in significant economic damage.
\end{abstract}

\section{Introduction}

From the geomorphological point of view the northern slope of Klin-and-Dmitrov Ridge as one of the orographical elements of Smolensk-and-Moscow Upland, is a favorable place for construction of pumped storage energy plants in the Moscow region. It has led to the fact that in the eighties last century, on the plateau-like massif which is cut off by valleys of the Dubna Rivers and Kunya River the Zagorsk pumped storage energy plant (ZaPSEP) was constructed to be properly under maintenance now. Stable and trouble-free maintenance of ZaPSEP-1 has proved the expediency of construction in this area $(900$ meters down the flow of Marten River) one more pumped storage energy plant - ZaPSEP-2 with the general lower pool for both energy plants (Figure 1).

Absolute marks of the surface of the plateau-like watershed make 250...260 metres and tower 100-110 metres over the bottoms of valleys. Considerable high-rise gradients have caused high kinetic energy of water streams that has led to the formation of numerous ravines that was promoted also by the existence of friable middle and the upper-quarter thin, the fluvial-and-glacial and lake-glacial deposits of the Moscow and Dnieper moraine.

${ }^{*}$ Corresponding author: lavrusevich@yandex.ru 
Carbon limestones on the site of the construction of the water-engineering system are at the depths from 150 to 300 metres [1]. Upper-Jurassic clay deposits block the coal deposits and act as a water emphasis. There is an alternation of sandy and clay deposits of the lower and top chalk above. The basis of a base plate of the building of ZaPSEP-2 under construction are middle-and-upperquarternary deposits which fill the deep cutting of the ancient pra-Marten River. The layer of deposits reaches 100 metres. Quarternary deposits have motley lithology-facial structure and complex structure. The layers unrestrained on stretching, with sharply changing stoutness, having roughly and small disperse composition of soil, their horizontal and slanting lamination, sharp change of lithology-facial differences, several water-bearing horizons, some of which are pressure head and change of hydraulic communication in stretching, rather dismembered surface and also high technogenic loading allows to refer engineering-geological conditions of the territory ZaPSEP-2 to the III category of complexity $[2,3]$.

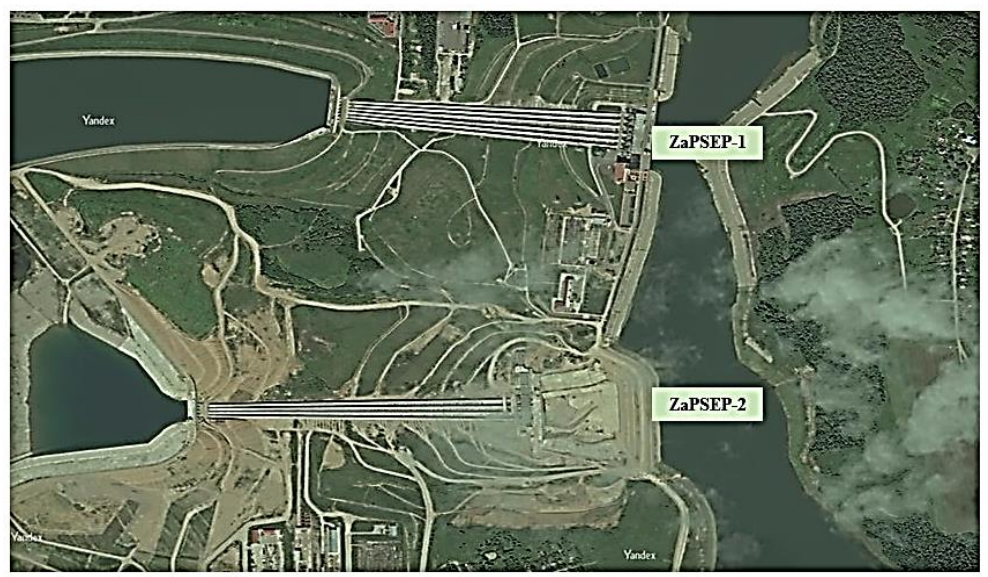

Fig. 1. Arrangement of pumped storage energy plants ZaPESP-1 and ZaPESP-2.

Carbon limestones on the site of the construction of the water-engineering system are at the depths from 150 to 300 metres [1]. Upper-Jurassic clay deposits block the coal deposits and act as a water emphasis. There is an alternation of sandy and clay deposits of the lower and top chalk above. The basis of a base plate of the building of ZaPSEP-2 under construction are middle-and-upperquarternary deposits which fill the deep cutting of the ancient pra-Marten River. The layer of deposits reaches 100 metres. Quarternary deposits have motley lithology-facial structure and complex structure. The layers unrestrained on stretching, with sharply changing stoutness, having roughly and small disperse composition of soil, their horizontal and slanting lamination, sharp change of lithology-facial differences, several water-bearing horizons, some of which are pressure head and change of hydraulic communication in stretching, rather dismembered surface and also high technogenic loading allows to refer engineering-geological conditions of the territory ZaPSEP-2 to the III category of complexity $[2,3]$.

\section{Materials and methods}

However, the launch of 7th and 8th ZaPSEP-2 units in 2013, similar to the launch of the two first units on ZaPSEP-1 was interfered by the "incident" which occurred on September 17, 2013 which has led to the unilateral sinking of the building of ZaPSEP-2 [1] (Fig. $2,3,3 \mathrm{a}$ ). The carrying out of soil (more than 5 thousand $\mathrm{m} 3$ ) from the basis of the right part of the base plate of the building of the plant the through underground erosive channel which 
has connected the water source and the area of carrying out with the formation of the cavity, which also took a part of the bulk soil of backfilling was the cause of the accident at ZaPSEP -2 under construction (the building shift different from the design situation).

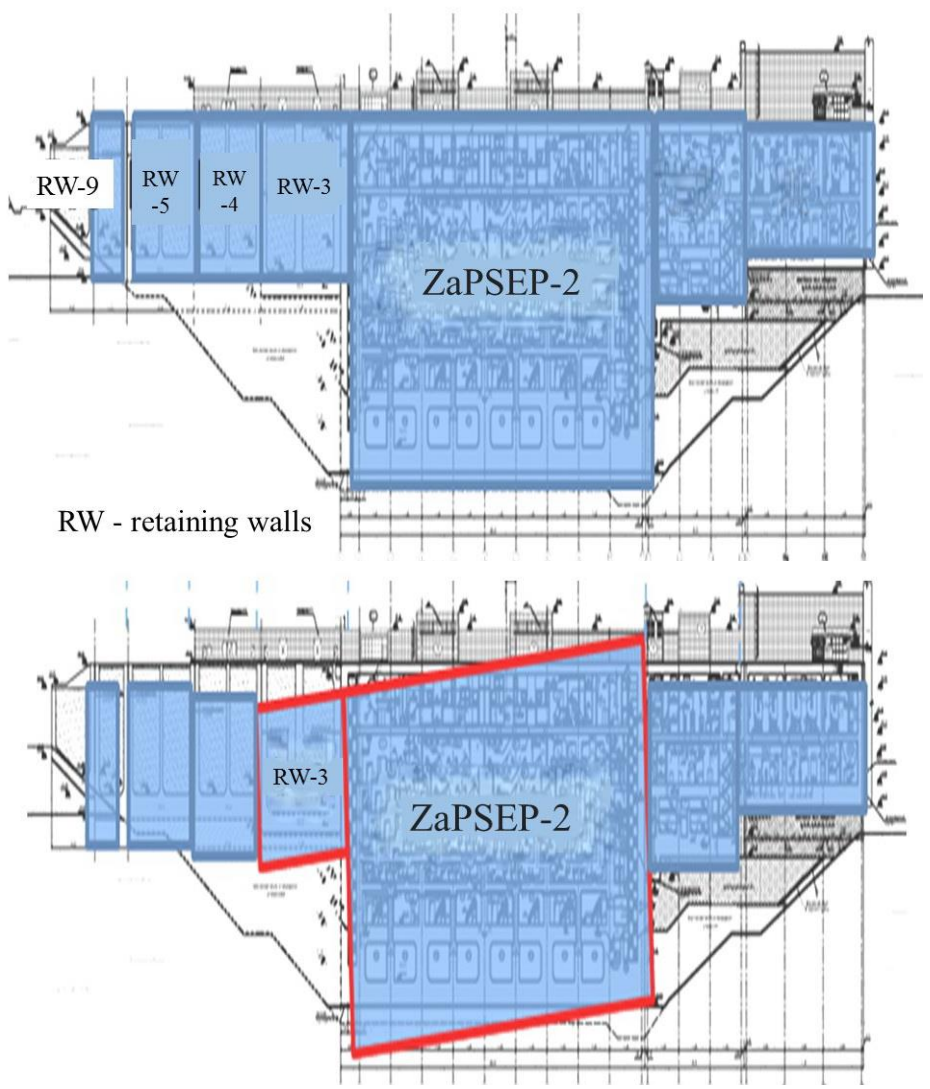

Fig. 2. Scheme of unilateral sinking of the building ZaPSEP-2 as the result of the incident in 2013 (according to A.V. Alexandrov, E.N. Belendira, etc, 2016) [1].

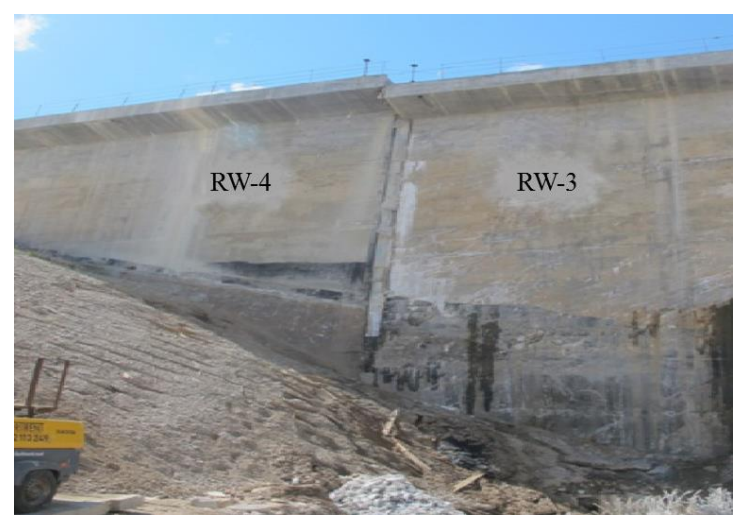

Fig. 3. Shift $(1.17 \mathrm{~m})$ in the zone of the adjunction of retaining walls of 3 and 4 (PS3 and PS4) is visible. Apparently from the scheme (Fig. 2) the main amplitude of shift is dated for the zone of adjunction RW3 of RW4. 
The volume of the soil, which was taken out from the apron and bulk soil of backfilling, was about 15 thousand $\mathrm{m} 3$. The total amount of the taken-out material was about 24.5 thousand $\mathrm{m} 3$, and under the building of the station cavities with the diameter up to $10 \mathrm{~m}$ were created [1] (Fig. 4).

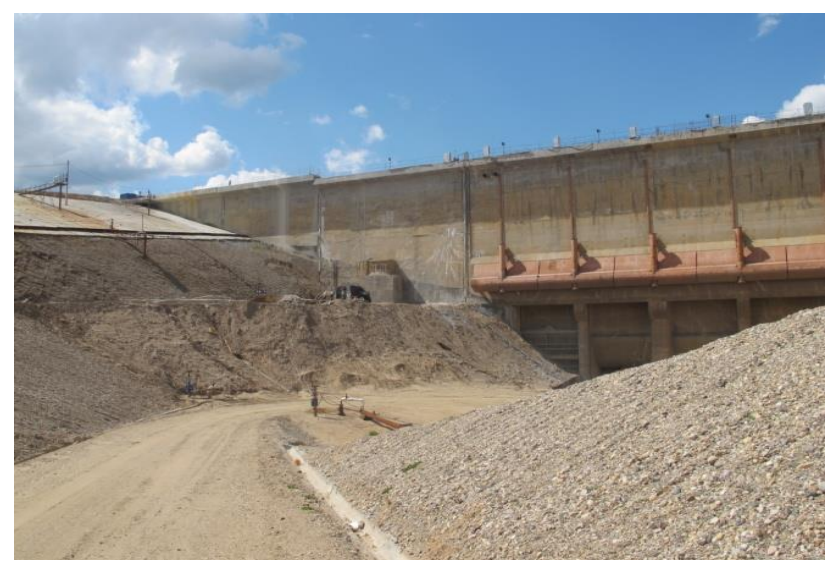

Fig. 4. The shift $(1.17 \mathrm{~m})$ in the zone of the adjunction of retaining walls of 3 and 4 (RW3 and RW4) is visible. Apparently from the scheme (Fig. 2) the main amplitude of shift is dated for the zone of adjunction RW 3 and RW4.

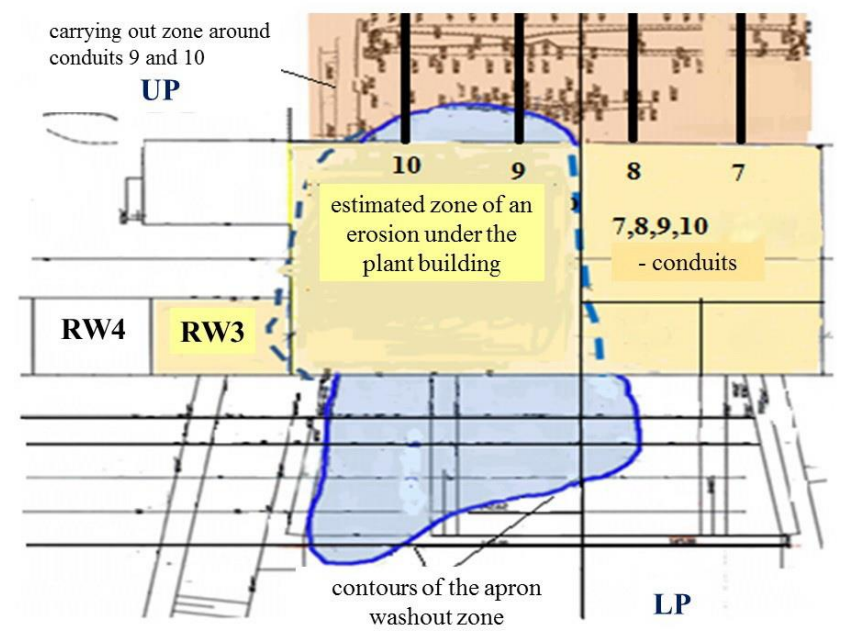

Fig. 4. Zone of erosive carrying out of soil of foundation of the building of the plant (UP - upper pond, LB - lower pond).

\section{Results}

This process was likely to be preceded by some "preparation" of the zone of erosive washout. Obviously, in this case we deal with the mechanical suffusion of fine particles of soil under the plant building. The following conditions are necessary for the development of this mechanical suffusion:

a) structural and textural inhomogeneity of rocks;

b) certain hydrodynamic force; 

[4].

c) existence of area of carrying out of the breeds, destroyed by a mechanical suffusion

At current situation on ZaPSEP-2 all these conditions have been created [13, 14].

Unlike the ZaPSEP-1 under maintenance during construction of the ZaPSEP-2 it was necessary to take into account the influence of the mode of fluctuation of level of the lower (general) pond of the ZaPSEP-1 and ZaPSEP-2 on the filtration modes in the basis and antifiltrational contours of ZaPSEP-2. Intensive oscillatory process (dumping and rise in water level up to $9 \mathrm{~m}$ down per a day) exerted impact on the stability of soil in the foundation of the building, reducing the antifiltrational stability. Some researchers prove, that such daily "swing" with the change of the hydraulic gradient has considerably reduced the probability of stabilization of the soil. Continuous daily change of the intense deformed condition of the soil massif has led to weakening of the structural communications in the rock formation as well as to emergence of fatigue effect $[5,6,7,8]$.

\section{Discussion}

The event, which took place at ZaPSEP-2 can be treated according to the concepts of hydropower. The environment of development of this suffusion-and-erosive destruction can be considered as consisting of two components: motionless one (suffusion unstable rocks) and mobile (the changing pressure and the subsequent water flow from the lower pond in top with a certain pressure) [8]. Considering the fact from the positions of thermodynamics, motionless is the component of an open system, then influence of pressure head water in the form of a suffusion consolidations of soil of the foundation is its power excitement by the means of the inflow of additional energy from the mobile components. At the same time mechanical potential energy of the motionless components increases at the expense of suffusion according the increase in porosity (the increase in hollowness of the soil). Then the saved-up potential energy passes into kinetic and there is a dissipation of mechanical energy of technogenic geosystem at the expense of the internal resistance of soil of the basis to deformations [9].

Internal filtrational destruction of water-saturated rocks the descending stream had "the smooth form" and certainly is connected with the slow infiltration of water of the lower pond through leaky joints or damages to the facing of structures as well as with insufficiently well working antifiltrational contour of soil in the backfilling. The griffin and the right end of the building of pumped storage power plant (the machine hall) can act as the indicator of suffusion process and poor antifiltrational contour.

\section{Conclusion}

The major condition, providing the development of the underground erosion at low permeability of the washed-away rocks is the existence of the initial through underground channel, which has to connect the water source of carrying out, and water has to move freely in the turbulent mode. The carrying out of soil of the basis has created an erosive tunnel, in which water with lower pond has directed with a huge force, entraining particles of soil of the created tunnel. Expanding this tunnel and deepening it is carried out by the means of taking out particles of soil.

Expansion of the erosive tunnel on the front of the building at the lower pond has reached $40 \mathrm{~m}$ with the depth of capture of soil up to 8-10 m. Such suffusion-and-erosive destruction on the front has continued in the form of discrete-and-cyclic erosive and landslide destruction with advance of its front in the direction opposite to the direction of a 
filtration stream, and that has caused that the water column has broken the 1.5 meter deep apron in the basis soil.

\section{References}

1. A.V. Alexandrov, E.N. Bellendir, S. Ya. Lashchenov, R. Sh. Alzhanov, Hydrotechnical construction 7, 2-10 (2016)

2. E. M. Sergeev, Engineering geology of the USSR. Platform regions of the European part of the USSR (Subsoil, Moscow, 1991)

3. The joint venture 47.13330.2012 Engineering researches for construction. Basic provisions. The staticized editorial office Construction Norms and Regulations 11-0296 (1996)

4. V.D. Lomtadze, Engineering geology. Engineering geodynamics (Subsoil, Leningrad, 1977)

5. A.N. Demidkova, Seasonal variations of inclinations of the basis of the water intake of the Zagorsk pumped storage power plant. Vesemnadtsatye Sergeevskiye of reading. Engineering geology and geoecology. Fundamental problems and applied tasks. The anniversary conference devoted to the 25 anniversary of formation of IGE RA (RUDN, Moscow, 2016)

6. A.N. Demidkova, I.V. Osika, Prospects of an integration of methods of natural observations for assessment of a condition of hydropower objects. Seventh scientific and technical conference (Hydropower, S.-Peterburg, 2012)

7. B.M. Kochetkov, S.M. Molodensky, V.I. Osika, Georisk 1, 22-28 (2009)

8. V. Osika, Assessment of technogenic impact from work of pumped storage power plant on the geological environment (on the example of the Zagorsk pumped storage power plant (Moscow, 2009)

9. V.P. Homenko, Regularities and forecast suffozionnykh of processes (GEOS, Moscow, 2003)

10. E.Yu. Nasynova, Hydrotechnical construction 6, 28-32 (2013)

11. S.S. Golovin, N.K. Rosenberg, Sergeevsky readings. Engineering geology and geoecology. Fundamental problems and applied 25, 263-266 (2016)

12. A.A. Makarova, G.A. Golodkovskaya, A.I. Yudkevich, Sergeevsky readings. International year of the planet Earth: problems of geoecology, engineering geology and hydrogeology, 159-162 (2006)

13. T. Verminskaya, V. Zinatullin, A. Kuhta, I. Rubtsov, E. Chibisova, Almanac of modern science and education 7, 37-39 (2008)

14. An. Mottayeva, As. Mottayeva, Problems of management of the state and municipal ownership at the present stage (MSUCE, Moscow, 2015) 